Maiorova, T., Stevens, F., Scherpbier, A., Zee, J. van der. The impact of clerkships on studentş' specialty preferences: what do undergraduates learn for their profession? Medical Education 2008, 42(6), 554-562

\begin{tabular}{|l|l|}
\hline Postprint Version & 1.0 \\
\hline Journal website & $\underline{\mathrm{http} / / \text { www3.interscience.wiley.com/cgi-bin/fulltext/119403498/PDFSTART }}$ \\
\hline Pubmed link & $\underline{\mathrm{http} / / \text { www.ncbi.nlm.nih.gov/pubmed/18435712 }}$ \\
\hline DOI & $10.1111 / \mathrm{j} .1365-2923.2008 .03008 . \mathrm{x}$ \\
\hline
\end{tabular}

This is a NIVEL certified Post Print, more info at http://www.nivel.eu

\title{
The impact of clerkships on students' specialty preferences: what do undergraduates learn for their profession?
}

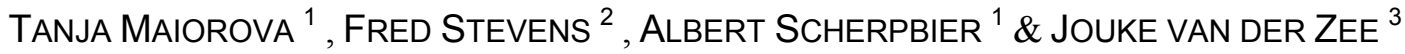 \\ ${ }^{1}$ Institute of Medical Education, Faculty of Medicine, University of Maastricht, Maastricht, \\ The Netherlands \\ ${ }^{2}$ Department of Health Care Studies, University of Maastricht, Maastricht, The Netherlands \\ 3 Netherlands Institute of Health Services Research, Utrecht, The Netherlands \\ Correspondence to Fred Stevens, University of Maastricht, Department of Educational \\ Development and Research, P.O. Box 616, 6200 MD, Maastricht, the Netherlands. \\ Tel: 003143388 5759; E-mail: fred.stevens@educ.unimaas.nl
}

\begin{abstract}
Objective Clinical experiences and gender have been shown to influence medical students' specialty choices. It remains unclear, however, which aspects of experiences make students favour some specialties and reject others. This study aimed to clarify the effects of clerkships on specialty choice and to identify explanatory factors.
\end{abstract}

Methods We carried out a longitudinal cohort study to collect data on career preferences and attitudes towards future careers among 3 cohorts of students before and after clerkships in surgery $(n=200)$, internal medicine $(n=277)$ and general practice $(n=184)$. Regression analyses were performed to identify the determinants of career choice and the role of gender.

Results Exposure to clinical settings encourages students to opt for a career in the corresponding specialty. Men were more stimulated than women by the general practice clerkship. Gender had no clear role as a predictor of career preference. The major predictor of career choice in all 3 specialties was positive evaluation of work-intrinsic factors. A preference for working with acute patients and technology-oriented work, prestige orientation and insignificance of a controllable lifestyle were determinants of a preference for surgery. Students with a preference for general practice had almost opposite preferences. Those who chose internal medicine favoured a controllable lifestyle.

Discussion Factors other than gender appear to drive specialty decisions. Work content, type of patients and lifestyle options play major roles. Consequently, along with teaching about the practice of medicine, the matching of specialty preferences with reality is an essential outcome of clerkships. 
Maiorova, T., Stevens, F., Scherpbier, A., Zee, J. van der. The impact of clerkships on studentş specialty preferences: what do undergraduates learn for their profession? Medical Education 2008, 42(6), 554-562

\section{INTRODUCTION}

Recent developments in the medical world include the declining popularity of general practice as a career and the gradually increasing number of women in medicine. ${ }^{1-3}$ These developments could lead to a potential misdistribution of the doctor workforce in health care services, an issue that revitalises the classic research question as to which factors affect the career choices of medical graduates. The types of factors that influence the career preferences of medical students range from demographic to institutional (medical school) and from micro (personality) to macro (societal) levels. ${ }^{4,5}$ Previous research highlighted work content and willingness to work with chronically ill patients as important determinants of choosing a career in general practice. By contrast, students who sought surgical training attached greater importance to prestige and career opportunities. ${ }^{6}$ There is also evidence that increased awareness of a specialty and clinical experiences during clerkships are associated with shifts in preferences and eventual specialty choice. ${ }^{7-9}$ Previous studies supported the assumption that general practice clerkships encourage students to pursue further training in this specialty. ${ }^{10,11}$ It is not clear, however, whether such a positive clerkship effect is equally observable for other specialties.

It is also unknown whether clerkship effects are different for men and women. Gender has always been an important determinant of career choice, with women more likely to prefer part-time work and opportunities to combine work and personal life. ${ }^{12,13}$ Men are typically more attracted by technical challenges, prestige and learning potential. ${ }^{14}$ In line with this, women tend to opt for careers in community-based areas and social medicine, whereas men are more inclined to prefer hospital-based specialties. ${ }^{14,15}$ A number of recent studies have suggested, however, that the impact of gender is declining and male and female students' attitudes and overall perceptions of specialties are becoming more alike. ${ }^{16,17}$ One reason for this may be that the quality of personal life has shown a substantial increase in importance for men. ${ }^{18}$ It looks now as if a controllable lifestyle with time for leisure and a fixed number of weekly hours has a stronger appeal for men than the traditional male medical career motivators, which include prestige, remuneration and length of training. ${ }^{19}$ Lifestyle and family factors are becoming more important in career decisions. ${ }^{12,20,21}$

In the present study we performed a comparative analysis of clerkships in general practice, internal medicine and surgery to examine:

1 specific versus generic impact of clerkships;

2 whether clerkship impact is different for male and female students, and

3 whether a clerkship affects students' specialty preferences.

\section{METHODS}

\section{Participants}

We surveyed medical students at the University of Maastricht, the Netherlands. Students were asked to complete a questionnaire before and after 10-week clerkships in surgery and internal medicine and a 12-week clerkship in general practice. We asked the students to complete the questionnaire during group meetings at the beginning and end of the clerkships. The doctors responsible for the organisation of the clerkships asked for consent. Questionnaires were then distributed before the meeting and collected afterwards.

New clerkship groups start every 2 (4 in general practice) weeks throughout the whole year. The surgery and internal medicine cohorts were surveyed between September 2004 and September or October 2005, respectively; the general practice cohort was surveyed earlier between September 2002 and July 2003. The numbers of participants are shown in Table 1.

[TABLE 1]

Although the sequence of clerkships is different for every student, the general practice clerkship always takes place in the second year of the clerkships period. Students who 
Maiorova, T., Stevens, F., Scherpbier, A., Zee, J. van der. The impact of clerkships on studentş' specialty preferences: what do undergraduates learn for their profession? Medical Education 2008, 42(6), 554-562

participated in internal medicine and surgery clerkships were involved in their first and second years of clerkships.

The cohorts of students involved in internal medicine and surgery clerkships overlapped to a certain degree: $47 \%$ of the surgery cohort also participated in the internal medicine clerkship, and $34 \%$ of the medical cohort participated in the surgery clerkship.

Because some questionnaires were not fully completed, student numbers in the analysis and tables vary slightly. An analysis of the data that included only students who fully completed the questionnaires did not modify the results presented in this article.

\section{Instrument}

The questionnaire, primarily based on previous studies cited in the Introduction, ${ }^{14,22}$ contained items on the following areas before and after the clerkships:

4 personal characteristics (age, gender);

5 type of patients ('To what degree do you prefer to take care of chronically ill, geriatric, acute patients etc?' 1 = not at all, 5 = very much);

6 type of care ('To what degree do you prefer palliative care, emergency care, technology-oriented work, scientific work, management etc?' $1=$ not at all, $5=$ very much);

7 future job ('To what degree do you consider these factors important to your future job: part-time work, income level, status, working hours, colleagues etc?' 1 = not at all, $5=$ very much);

8 evaluation of the work of a surgeon/internist/general practitioner (GP) ('Do you like the following aspects of being a surgeon/internist/GP: type of patients, variety of work, status, income etc?' $1=$ not at all, $5=$ very much);

9 preferred specialty ('What specialty do you prefer?'), and

10 likelihood of becoming a specialist, according to the corresponding specialty ('How likely are you to become a surgeon/internist/GP?' $1=$ not at all, $5=$ very likely).

Factor analysis (varimax rotation) and scaling techniques were used to construct attitude variables from the questions about students' attitudes towards 3 main categories:

- preferred patient categories;

- preference for type of work in the future, and

- evaluation of general practice, surgery and internal medicine as a profession.

The items (5-point Likert scales), attitude variables (composed of sum scores) and reliabilities (Cronbach's alpha) are presented in Appendix 1.

The questionnaires administered at the start and end of the clerkship were basically identical. After the clerkships the students were additionally asked to appraise the influence of clerkship preceptors as role models ('Evaluate the skills of your preceptor: clinical, management, didactic and communication skills', on a scale of $1-5$ where $1=$ insufficient, $5=$ good).

The construct validity of the questionnaire was checked by means of factor analysis (Appendix 1). ${ }^{23}$

\section{Statistical analysis}

We analysed data from students who completed both the first and second questionnaires for a rotation in surgery, internal medicine or general practice. spss (SPSS Inc, Chicago, IL, USA) was used to analyse the data.

ancova was performed to test the influence of the 2 possible confounding variables: the year of rotations (first or second) and overlap of cohorts. These variables had no significant influence on the results of analysis.

We calculated McNemar's chi-square to examine differences in specialty preferences before and after clerkships for male and female students. ${ }^{24}$ When the frequencies were low, 
Maiorova, T., Stevens, F., Scherpbier, A., Zee, J. van der. The impact of clerkships on studentş' specialty preferences: what do undergraduates learn for their profession? Medical Education 2008, 42(6), 554-562

binominal tests were performed. Male and female students' preferences were examined by calculating relative risk ratios ( $\mathrm{RR}$, women : men).

The McNemar-Bowker test of symmetry (chi-square) was used to test the differences in self-perceived likelihood of becoming a particular specialist before and after the clerkships.

Finally, logistic regression analysis was performed with students' self-perceived likelihood of becoming a GP, surgeon or internist before and after the rotations as dependent variables and gender and students' attitudes as independent variables.

\section{RESULTS}

\section{Specialty preferences}

Figure 1 shows the distribution of specialty preferences before and after rotations. After all 3 rotations there was an overall increase in preference for the specialty of the rotation just completed $(\mathrm{P}<0.01)$. Preference for surgery increased from $30 \%$ to $44 \%(\mathrm{P}<0.05)$ for male students and from $9 \%$ to $22 \%(\mathrm{P}<0.01)$ for female students. After the rotations women were less likely than men $(R R=0.059)$ to prefer surgery and more likely than men $(R R=1.53)$ to prefer general practice. Preference for internal medicine was almost equal for men and women $(\mathrm{RR}=1.07)$.

\section{[FIGURE 1]}

\section{Perceived likelihood of becoming a GP, surgeon or internist}

In addition to indicating their specialty preferences, we asked the students to indicate selfperceived likelihood of becoming a surgeon, internist or GP, both before and after clerkships.

The changes in perceived likelihood before and after the clerkships (Table 2) were significant for all 3 specialties: surgery $(\mathrm{P}<0.01)$; internal medicine $(\mathrm{P}=0.045)$, and general practice $(\mathrm{P}<0.01)$.

\section{[TABLE 2]}

After the surgical clerkship the likelihood increased in $31 \%$ of students and remained unchanged in $59 \%$ of students (54\% of these students reported a positive likelihood before as well as after the rotation). The increase in inclination to become a surgeon was significant only for women $(\mathrm{P}<0.01)$, although more men than women were planning a career in surgery.

After the internal medicine clerkship the perceived likelihood of choosing internal medicine was unchanged in $49 \%$ of students, with $62 \%$ of these students expressing positive views about becoming an internist. There was no significant increase in likelihood for either gender tested separately.

The perceived likelihood of choosing a career in general practice showed a higher significant increase among male $(38 \%, \mathrm{P}<0.1)$ than female students $(22 \%, \mathrm{P}<0.05)$. However, the majority of the students expressing a preference for general practice were female. A total of $63 \%$ of students reported an unchanged inclination for a career in general practice, with nearly half of them willing to become a GP.

\section{Predictors of specialty preference}

Table 3 shows factors predicting students' perceived likelihood of becoming a surgeon, internist or GP before and after the respective clerkships.

\section{TABLE 3]}

In all 3 clerkships positive evaluation of intrinsic work factors (variety of work and patients, treatments) for the specialty was a strong positive predictor. 
Maiorova, T., Stevens, F., Scherpbier, A., Zee, J. van der. The impact of clerkships on studentş' specialty preferences: what do undergraduates learn for their profession? Medical Education 2008, 42(6), 554-562

The motivating influence of extrinsic work factors (i.e. status, income and career prospects) was only positively related to the perceived likelihood of becoming a GP before the clerkship. After the rotation this effect had disappeared in favour of intrinsic factor motivation, which suggests that students changed their initial views of general practice as a profession. A similar effect was observed for the surgery rotation.

Table 3 also shows that a preference for working with acute patients and a favourable orientation towards technology were positively related to the perceived likelihood of becoming a surgeon, both before and after the clerkship. By contrast, a preference for working with chronic patients and palliative care was a negative determinant of the perceived likelihood of becoming a surgeon. Data for general practice showed the opposite relationships.

With respect to work conditions, preference for a controllable lifestyle was negatively related to the perceived likelihood of becoming a surgeon both before and after the surgical rotation, whereas an orientation towards prestige was found to have a positive effect on the perceived likelihood of becoming a surgeon after the rotation. After the GP rotation an orientation towards prestige was negatively related to the perceived likelihood of becoming a GP, whereas a positive effect before the internal medicine rotation had disappeared after the clerkship. The relationship between a preference for a controllable lifestyle and the perceived likelihood of becoming an internist changed from negative before the rotation to positive after the clerkship. A preference for part-time work and regular working hours was not related to the perceived likelihood of becoming a GP.

Neither gender nor role modelling on the part of clerkship preceptors showed a substantial relationship with the perceived likelihood of a career in any of the specialties. Role modelling only affected the perceived likelihood of becoming an internist, whereas gender (male) predicted the likelihood of becoming a surgeon.

Finally, adjusted $r^{2}$ indicated that the independent variables were stronger predictors of the perceived likelihood of becoming a GP or surgeon, both before and after the clerkships, than of the perceived likelihood of choosing a career in internal medicine.

\section{DISCUSSION}

This study underscores the importance of clinical experiences for career considerations. ${ }^{7}$ Our study showed similar patterns of change in specialty preferences for general practice, surgery and internal medicine: students were encouraged by the clerkship to consider a future career in the specialty of the rotation. Although the perceived likelihood of opting for a career in general practice, surgery or internal medicine increased after the respective clerkships, the views of the majority of the students remained largely unchanged. It is likely that many students saw their ideas regarding a specialty, whether positive or negative, reinforced during the clerkship and, as a result, did not alter their preferences.

Clerkship effects were different for male and female students. Relatively more male than female students preferred a career in surgery, and more female than male students preferred a career in general practice. It was less expected that a higher percentage of female students would report an increased inclination towards becoming a surgeon and a higher percentage of male students would indicate an increased likelihood of going into general practice after the rotations. In fact, we observed that preferences were spread according to a classic gender pattern: men opted more for surgery and women for general practice. However, relatively more female than male students discovered new attractive aspects of surgery and relatively more male than female students reported a higher likelihood of becoming a GP. This underscores the enlightening role of clerkships in career choices.

Our findings could not substantiate the hypothesis that gender is associated with the perceived likelihood of entering a specific specialty. However, specialty preferences reflected a certain gender-related pattern, with men favouring surgery, women favouring general practice and both genders exhibiting equal degrees of inclination for internal 
Maiorova, T., Stevens, F., Scherpbier, A., Zee, J. van der. The impact of clerkships on studentş' specialty preferences: what do undergraduates learn for their profession? Medical Education: 2008, 42(6), 554-562

medicine. Apparently, factors other than gender are more essential in the decision-making process. In all 3 clerkships a positive view of factors that are intrinsic to the work was a positive predictor of the likelihood of opting for a specialty. In general practice this effect was only observed after the rotation, which may indicate that before the clerkship students did not have a clear idea of what general practice might entail. From our experiences, we believe that too often the prevailing view among students is that a GP is a 'dull' generalist who refers the 'interesting' patients to hospital-based specialists. Apparently, experiences in primary care settings promote an interest in general practice and show it to have advantages that were not considered or known of beforehand. ${ }^{15,22,25,26}$

Students indicating a high likelihood of becoming a surgeon were consistently negative about working with chronic patients and positive with regard to emergency care and technology-oriented work. This contrasts with students who were attracted to general practice. After the general practice clerkship, willingness to deal with chronic problems, longterm contacts with patients and providing continuity of care were associated with a high perceived likelihood of becoming a GP. Apparently, the GP clerkship strengthens an interest in primary care medicine.

After the internal medicine rotation, students with a high perceived likelihood of choosing internal medicine showed a preference for a controllable lifestyle. After the surgery rotation, there was a more positive relationship between perceived likelihood of becoming a surgeon and a preference for prestige and income than there had been before the clerkship. Surgery appears to require a great deal of time, effort and devotion, which does not allow for a controllable lifestyle. ${ }^{27}$ Students saw their ideas about surgery confirmed, whereas during the internal medicine clerkship students may have appreciated the more favourable opportunities for part-time work and leisure time.

Gender differences regarding career choice appear to be not only based on typical male and female choices but to be a combination of attitudinal factors, such as type of preferred patients and work (technology-oriented work and emergency situations versus chronic patients and palliative care) and lifestyle preferences (part-time work or career and income orientation). These findings substantiate the notion that the function of clerkship is not only to give students experience in the practice of medicine but also to make them more aware of, and help them decide on, their preferences for different types of medical work, patients and settings. In addition to medical skills, students also acquire a sense of professional identity and look for the specialty they fit. ${ }^{28}$ Medicine is unique among the professions in providing such a broad comparative opportunity. As the results of this study show, students obtain an idea of the types of patients they prefer to work with, the types of work they like and dislike, and the opportunities to combine work and leisure as a specialist. Not surprisingly, students choose a specialty on the basis of the work content experienced during a clerkship. The results also show that the importance of extrinsic aspects of a specialty (status, career, remuneration) diminishes after clerkship. It is the content of the work that matters.

In this study, attitude-related factors seem to offer a better explanation for the perceived likelihood of becoming a surgeon or a GP than of becoming an internist. Perhaps students who opt for general practice or surgery have a clearer picture of the values and expectations that pertain to their chosen specialty. By contrast, undergraduates who report a high likelihood of becoming an internist may be attracted by a combination of the advantages of general practice and hospital work. It is not uncommon for graduates to gain some clinical experience in internal medicine before deciding on their final specialty choice. This may explain the discrepancy in this study between students' attitudes and the perceived likelihood of becoming an internist. Besides learning from experiences in medical practice, matching students' expectations with clinical practice should be an important objective and outcome of clinical clerkships.

Our study has several limitations. Firstly, we used different cohorts, and 2 of them partly overlapped. Secondly, we were unable to measure the impact of the sequence of clerkships on the students' preferences. Every student has a unique clerkships schedule and, for this 
Maiorova, T., Stevens, F., Scherpbier, A., Zee, J. van der. The impact of clerkships on studentş specialty preferences: what do undergraduates learn for their profession? Medical Education: 2008, 42(6), 554-562

reason, it was not possible to analyse accurately the influence of each clerkship at the moment of our survey. However, as already indicated, neither the overlap, nor the year of rotations had a significant influence on the results. A third limitation is that we surveyed cohorts from 1 university only. Notwithstanding this, our findings build upon the existing literature. More research is needed to substantiate our results.

CONTRIBUTORS: all authors contributed to the conception and design of the study, the collection, analysis and interpretation of data, and the critical revision of the manuscript. All authors approved the final paper.

ACKNOWLEDGEMENTS: we would like to thank the Departments of Internal Medicine, Surgery and General Practice at Maastricht University for their contributions in distributing the questionnaires for this study.

FUNDING: this study was funded by the Institute of Medical Education, Faculty of Medicine, Maastricht University.

CONFLICTS OF INTEREST: none.

ETHICAL APPROVAL: not applicable.

\section{OVERVIEW}

\section{What is already known on this subject}

Clinical experiences influence students' specialty choices. It remains unclear, however, what causes students to choose some specialties and reject others.

\section{What this study adds}

The results of this study indicate that students' specialty choices are mainly influenced by a combination of different (gender-related) factors, such as work content, type of patient and lifestyle options. Students use clerkships to learn about practising medicine and to discover the benefits and downsides of different professional careers. Clerkship supervisors might use these insights to be more proactive in attracting students as trainees to their disciplines.

\section{Suggestions for further research}

Further research might examine which clerkship-related factors determine students' ultimate career choices.

\section{REFERENCES}

1 Van Offenbeek M., Kiewiet D, Oosterhuis M. The compatibility of future doctors' career intentions with changing health care demands. Med Educ 2006;40:530-8.

2 Sobral D. Influences on choice of surgery as a career: a study of consecutive cohorts in a medical school. Med Educ 2006;40:522-9.

3 Lambert TW, Davidson JM, Evans J, Goldacre MJ. Doctors' reasons for rejecting initial choices of specialties as longterm careers. Med Educ 2003;37:312-8.

4 Bland C, Meurer L, Maldonado G. Determinants of primary care specialty choice: a nonstatistical meta-analysis of the literature. Acad Med 1995;70:620-41.

5 Henderson M, Hunt D, Williams J. General internists influence students to choose primary care careers: the power of role modelling. Am J Med Sci 1996;101:648-53.

6 Azizzadeh A, McCollum C, Miller C, Holliday K, Shilstone H, Lucci A. Factors influencing career choice among medical students interested in surgery. Curr Surg 2003;60 (2):210-3.

7 Williams S, Saizow R, Ross L, Deci E. Motivation underlying career choice for internal medicine and surgery. Soc Sci Med 1997;45 (11):1705-13.

8 Schwartz M, Linzer M, Babbott D, Divine G, Broadhead W. The impact of an ambulatory rotation on medical student interest in internal medicine. The Society of General Internal Medicine Task Force on Career Choice in Internal Medicine. J Gen Intern Med 1995;10:542-9.

9 Mihalynuk T, Leung G, Franser J, Bates J, Snadden D. Free choice and career choice: clerkship electives in medical education. Med Educ 2006;40:1065-71. 
Maiorova, T., Stevens, F., Scherpbier, A., Zee, J. van der. The impact of clerkships on studentş' specialty preferences: what do undergraduates learn for their profession? Medical Education: 2008, 42(6), 554-562

10 Kassebaum D, Szenas P, Schuchert M. Determinants of the generalist care intentions of 1995 graduating medical students. Acad Med 1996;71:198-209.

11 Ellsbury K, Carline J, Irby D, Stritter F. Influence of third-year clerkships on medical student specialty preferences. Adv Health Sci Educ Theory Pract 1998;3:177-86.

12 Ek EW, Ek ET,Mackay SD. Undergraduate experience of surgical teaching and its influence on career choice. Aust N Z J Surg 2005;75 (8):713-8.

13 Gorenflo D, Ruffin M, Sheets K. A multivariate model for specialty preference by medical students. J Fam Pract 1994;39:570-6.

14 Baxter N, Cohen R, McLeod R. The impact of gender on the choice of surgery as a career. Am J Surg 1996;172:373-6.

15 Howe A, Ives G. Does community-based experience alter career preference? New evidence from a prospective longitudinal cohort study of undergraduate medical students. Med Educ 2001;35:391-7.

16 Ehrlich P, Seideman P. Deconstructing surgical education - teacher quality really matters: implications for attracting medical students to surgical careers. Am Surg 2006;72 (5):430-4.

17 Davis B, Nelson D, Sahler O, Goldberg R, Greenberg L. Do clerkship experiences affect medical students' attitudes toward chronically ill patients? Acad Med 2001;76 (8):815-20.

18 Brown A, Swinyard W, Ogle J. Women in academic medicine: a report of focus groups and questionnaires, with conjoint analysis. J Women's Health 2003;12 (10):999-1008.

19 Dorsey E, Jarjoura D, Rutecki G. Influence of controllable lifestyle on recent trends in specialty choice by US medical students. JAMA 2003;290 (9):1173-8.

20 Brundage S, Lucci A, Miller C, Azizzadeh A, Spain D, Kozar R. Potential targets to encourage a surgical career. J Am Coll Surg 2005;200 (6):946-53.

21 Wendel T, Godellas C, Prinz R. Are there gender differences in choosing a surgical career? Surgery 2003;134 (4):591-6.

22 Morrison J, Murray T. Career preferences of medical students: influence of a new fourweek attachment in general practice. Br J Gen Pract 1996;46:721-5.

23 Rummel R. Applied Factor Analysis. Evanston, IL: Northwestern University Press 1970;19-21.

24 Siegel S, Castellan N. Non-parametric Statistics for the Behavioral Sciences, 2nd edn. New York: McGraw Hill 1988;75-87.

25 Xu G, Hojat M, Brigham T, Veloski J. Factors associated with changing levels of interest in primary care during medical school. Acad Med 1999;74:1011-5.

26 Campos-Outcalt D, Senf J, Watkins A, Bastacky S. The effects of medical school curricula, faculty role models, and biomedical research support on choice of generalist physician careers: a review and quality assessment of the literature. Acad Med 1995;70:611-9.

27 Klass P. A Not Entirely Benign Procedure. Four Years as a Medical Student. New York: Plume, Penguin Group 2000;137-45.

28 Dornan T, Boshuizen H, King N, Scherpbier A. Experience-based learning: a model linking the processes and outcomes of medical students' workplace learning. Med Educ 2007;41 (1):84-91. 
Maiorova, T., Stevens, F., Scherpbier, A., Zee, J. van der. The impact of clerkships on students' specialty preferences: what do undergraduates learn for their profession? Medical Education: 2008, 42(6), 554-562

\section{APPENDIX 1}

Scales, items and reliabilities (alpha) concerning students' attitudes

\begin{tabular}{|c|c|c|c|c|}
\hline Scale & Items & $\begin{array}{l}\text { Alpha } \\
\text { general } \\
\text { practice }\end{array}$ & $\begin{array}{l}\text { Alpha } \\
\text { internal } \\
\text { medicine }\end{array}$ & $\begin{array}{r}\text { Alpha } \\
\text { surgery }\end{array}$ \\
\hline \multicolumn{5}{|c|}{ Preferred patient category and type of work } \\
\hline \multirow{4}{*}{$\begin{array}{l}\text { Chronically ill } \\
\text { patients and palliative } \\
\text { care }\end{array}$} & Chronically ill patients & \multirow[t]{4}{*}{0.72} & \multirow[t]{4}{*}{0.65} & \multirow[t]{4}{*}{0.68} \\
\hline & Geriatric patients & & & \\
\hline & Palliative care & & & \\
\hline & $\begin{array}{l}\text { Longterm contacts with } \\
\text { patients }\end{array}$ & & & \\
\hline \multirow{5}{*}{$\begin{array}{l}\text { Acute patients and } \\
\text { technology-oriented } \\
\text { work }\end{array}$} & Technical activities & \multirow[t]{5}{*}{0.75} & \multirow[t]{5}{*}{0.73} & \multirow[t]{5}{*}{0.69} \\
\hline & Highly specialised work & & & \\
\hline & $\begin{array}{l}\text { Availability of personnel } \\
\text { and equipment }\end{array}$ & & & \\
\hline & Emergency care & & & \\
\hline & Acute patients & & & \\
\hline \multicolumn{5}{|c|}{ Preferred work conditions in the future } \\
\hline \multirow[t]{3}{*}{ Prestige orientation } & Income & \multirow[t]{3}{*}{0.70} & \multirow[t]{3}{*}{0.65} & \multirow[t]{3}{*}{0.61} \\
\hline & Career opportunities & & & \\
\hline & High status & & & \\
\hline \multirow{3}{*}{$\begin{array}{l}\text { Controllable lifestyle } \\
\text { orientation }\end{array}$} & Part-time work & \multirow[t]{3}{*}{0.76} & \multirow[t]{3}{*}{0.66} & \multirow[t]{3}{*}{0.66} \\
\hline & Regular working hours & & & \\
\hline & Leisure time & & & \\
\hline \multicolumn{5}{|c|}{ Evaluation of becoming a general practitioner/internist/surgeon } \\
\hline \multirow[t]{5}{*}{$\begin{array}{l}\text { Work-intrinsic } \\
\text { factors }\end{array}$} & $\begin{array}{l}\text { Variety of patients and } \\
\text { disorders }\end{array}$ & \multirow[t]{5}{*}{0.68} & \multirow[t]{5}{*}{0.73} & \multirow[t]{5}{*}{0.76} \\
\hline & $\begin{array}{l}\text { Contacts with family of } \\
\text { patients }\end{array}$ & & & \\
\hline & Individual treatments & & & \\
\hline & Variety of work & & & \\
\hline & $\begin{array}{l}\text { Collaboration and } \\
\text { communication with } \\
\text { colleagues }\end{array}$ & & & \\
\hline \multirow{3}{*}{$\begin{array}{l}\text { Work-extrinsic } \\
\text { factors }\end{array}$} & High status & \multirow[t]{3}{*}{0.63} & \multirow[t]{3}{*}{0.67} & \multirow[t]{3}{*}{0.70} \\
\hline & Income & & & \\
\hline & Career opportunities & & & \\
\hline
\end{tabular}


Maiorova, T., Stevens, F., Scherpbier, A., Zee, J. van der. The impact of clerkships on students' specialty preferences: what do undergraduates learn for their profession? Medical Education 2008, 42(6), 554-562

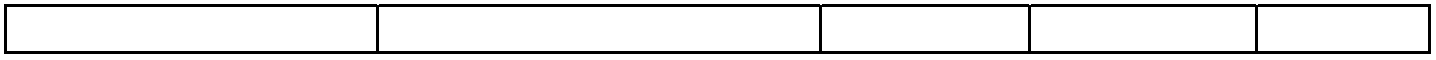

\section{TABLES}

\begin{tabular}{|c|c|c|c|c|c|}
\hline \multirow[b]{2}{*}{ Specialty } & \multirow[b]{2}{*}{$\begin{array}{l}\text { No. of clerkship } \\
\text { students }\end{array}$} & \multirow[b]{2}{*}{$\begin{array}{l}\text { Neutral } \\
\text { losses }\end{array}$} & \multicolumn{2}{|l|}{ Obtained questionnaires } & \multirow{2}{*}{$\begin{array}{l}\text { Completed } \\
\text { questionnaires } \\
\text { before and } \\
\text { after clerkships }\end{array}$} \\
\hline & & & Before the clerkship & After the clerkship & \\
\hline Surgery & 370 (68\% women) & 45 & 325 (66\% women) & 200 (67\% women) & 178 \\
\hline Internal medicine & 347 (68\% women) & 23 & 324 (72\% women) & 277 (74\% women) & 247 \\
\hline General practice & 206 (55\% women) & 3 & 203 (55\% women) & 184 (56\% women) & 168 \\
\hline Total & 923 & 71 & 852 & 661 & 593 \\
\hline
\end{tabular}

Table 2 Changes (in percentages) in perceived likelihood of becoming a general practitioner or internist or surgeon after clerkships in these specialties

\begin{tabular}{|c|c|c|c|}
\hline & Surgery & Internal medicine & General practice \\
\hline & $\begin{array}{l}\text { Total (men/women) } \\
\%\end{array}$ & $\begin{array}{l}\text { Total (men/women) } \\
\%\end{array}$ & $\begin{array}{l}\text { Total (men/women) } \\
\%\end{array}$ \\
\hline Less likely & $10(11 / 9)$ & $21(21 / 21)$ & $8(5 / 10)$ \\
\hline Unchanged & $59(65 / 56)$ & $49(55 / 47)$ & $63(57 / 68)$ \\
\hline More likely & $31(24 / 35)$ & $30(24 / 32)$ & $29(38 / 22)$ \\
\hline $\begin{array}{l}\text { Total } n \\
(100 \%)\end{array}$ & $\mathrm{n}=200(66 / 134)$ & $\mathrm{n}=277(70 / 207)$ & $\mathrm{n}=184(79 / 105)$ \\
\hline
\end{tabular}

Table 3 Multiple regression analysis. The dependent variables are the perceived likelihood of becoming a general practitioner, internist or surgeon before and after the clerkships

\begin{tabular}{|c|c|c|c|c|c|c|}
\hline \multirow[t]{2}{*}{$\begin{array}{l}\text { Independent } \\
\text { variables }\end{array}$} & \multicolumn{2}{|c|}{ Surgery $(n=178)$} & \multicolumn{2}{|c|}{$\begin{array}{l}\text { Internal medicine } \\
(\mathrm{n}=248)\end{array}$} & \multicolumn{2}{|c|}{$\begin{array}{l}\text { General practice } \\
(\mathrm{n}=175)\end{array}$} \\
\hline & Before & After & Before & After & before & after \\
\hline Gender & $-0.168^{*}$ & -0.082 & -0.101 & -0.062 & 0.127 & -0.046 \\
\hline \multicolumn{7}{|c|}{ Type of work and patients } \\
\hline $\begin{array}{l}\text { Chronically } \\
\text { ill patients and } \\
\text { palliative care }\end{array}$ & $-0.194 \dagger$ & $-0.210 \dagger$ & $0.129^{*}$ & 0.029 & 0.121 & $0.170 \dagger$ \\
\hline $\begin{array}{l}\text { Acute } \\
\text { patients and } \\
\text { technology- } \\
\text { oriented work }\end{array}$ & $0.319 \dagger$ & $0.255 \dagger$ & -0.002 & -0.006 & $-0.220 \dagger$ & $-0.267 \dagger$ \\
\hline \multicolumn{7}{|c|}{ Preferred work conditions } \\
\hline $\begin{array}{l}\text { Prestige } \\
\text { orientation }\end{array}$ & 0.022 & $0.161^{*}$ & $0.227^{*}$ & 0.020 & -0.089 & $-0.146^{*}$ \\
\hline
\end{tabular}


Maiorova, T., Stevens, F., Scherpbier, A., Zee, J. van der. The impact of clerkships on students' specialty preferences: what do undergraduates learn for their profession? Medical Education: 2008, 42(6), 554-562

\begin{tabular}{|c|c|c|c|c|c|c|}
\hline \begin{tabular}{l}
\multicolumn{1}{c}{ Controllable } \\
lifestyle \\
orientation
\end{tabular} & $-0.183^{*}$ & $-0.243^{\dagger}$ & -0.065 & $0.134 *$ & 0.116 & 0.081 \\
\hline \multicolumn{7}{|c|}{ Evaluation of becoming a general practitioner/internist/surgeon } \\
\hline $\begin{array}{l}\text { Work- } \\
\text { intrinsic factors }\end{array}$ & $0.165^{*}$ & $0.209^{\dagger}$ & $0.324^{\dagger}$ & $0.345^{\dagger}$ & 0.115 & $0.332^{\dagger}$ \\
\hline $\begin{array}{l}\text { Work- } \\
\text { extrinsic factors }\end{array}$ & $0.147 *$ & -0.033 & -0.099 & 0.000 & $0.220^{\dagger}$ & 0.125 \\
\hline \multicolumn{7}{|l|}{ Role model } \\
\hline $\begin{array}{l}\text { Clinical and } \\
\text { didactic skills }\end{array}$ & & 0.081 & & $0.147^{*}$ & & -0.012 \\
\hline $\begin{array}{l}\text { Scientific } \\
\text { expertise }\end{array}$ & & 0.079 & & -0.044 & & 0.005 \\
\hline Adjusted r2 & 0.40 & 0.48 & 0.19 & 0.17 & 0.34 & 0.48 \\
\hline
\end{tabular}


Maiorova, T., Stevens, F., Scherpbier, A., Zee, J. van der. The impact of clerkships on studentş' specialty preferences: what do undergraduates learn for their profession? Medical Education: 2008, 42(6), 554-562

Figure 1 Specialty preferences before and after clerkships in general practice, internal medicine and surgery

Preferences of male students

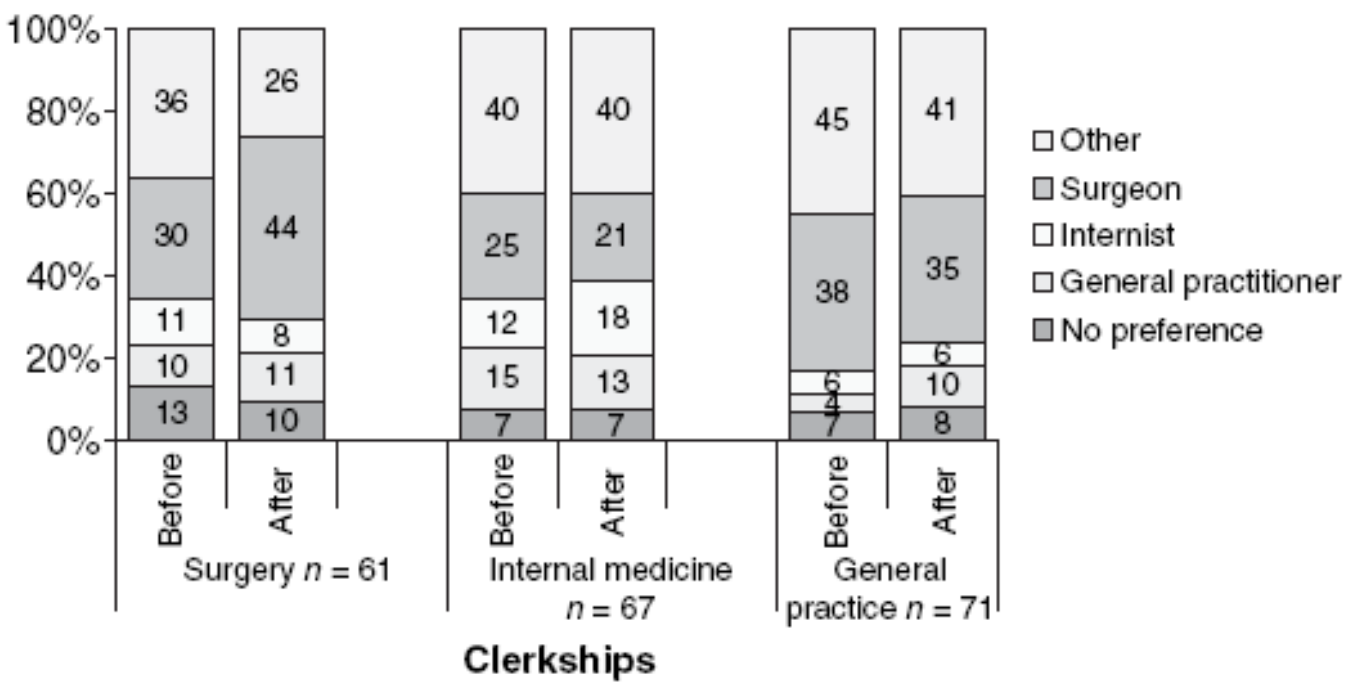

\section{Preferences of female students}

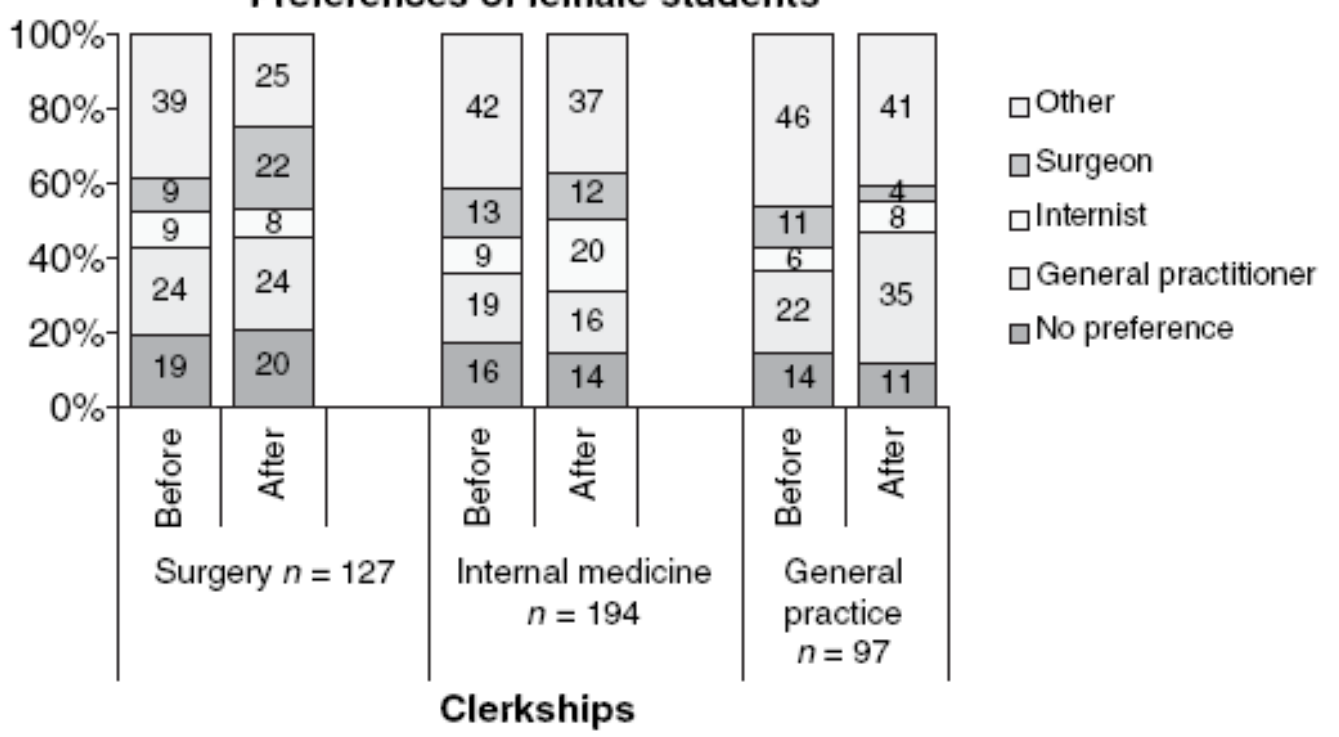

